\title{
Article
}

\section{A Lower Temperature FDM 3D Printing for the Manufacture of Patient-Specific Immediate Release Tablets}

Okwuosa, Tochukwu Chijioke, Stefaniak, Dominika, Arafat, Basel, Isreb, Abdullah, Wan, Ka-Wai and Albed Alhnan, Mohamed

Available at http://clok.uclan.ac.uk/15307/

Okwuosa, Tochukwu Chijioke, Stefaniak, Dominika, Arafat, Basel, Isreb, Abdullah ORCID: 0000-0001-9939-6161, Wan, Ka-Wai and Albed Alhnan, Mohamed (2016) A Lower Temperature FDM 3D Printing for the Manufacture of Patient-Specific Immediate Release Tablets. Pharmaceutical Research, 33 (11). pp. 2704-2712. ISSN 0724-8741

It is advisable to refer to the publisher's version if you intend to cite from the work. http://dx.doi.org/10.1007/s11095-016-1995-0

For more information about UCLan's research in this area go to http://www.uclan.ac.uk/researchgroups/ and search for <name of research Group>.

For information about Research generally at UCLan please go to http://www.uclan.ac.uk/research/

All outputs in CLoK are protected by Intellectual Property Rights law, including Copyright law. Copyright, IPR and Moral Rights for the works on this site are retained by the individual authors and/or other copyright owners. Terms and conditions for use of this material are defined in the policies page. 
RESEARCH PAPER

\section{A Lower Temperature FDM 3D Printing for the Manufacture of Patient-Specific Immediate Release Tablets}

Tochukwu C Okwuosaํ, Dominika Stefaniak¹, Basel Arafat ${ }^{1}$, Abdullah Isreb¹, Ka-Wai Wan ${ }^{1}$, Mohamed A Alhnan ${ }^{1 *}$

${ }^{1}$ School of Pharmacy and Biomedical Sciences, University of Central Lancashire, Preston, Lancashire, UK

${ }^{*}$ Corresponding author: MAlbedAlhnan@uclan.ac.uk 


\section{ABSTRACT}

Purpose. The fabrication of a ready-to-use immediate release tablets via 3D printing provides a powerful tool to on-demand individualization of dosage form. This work aims to adapt a widely used pharmaceutical grade polymer, polyvinylpyrrolidone (PVP), for instant on-demand production of immediate release tablets via FDM 3D printing.

Methods. Dipyridamole or theophylline loaded filaments were produced via processing a physical mixture of API (10\%) and PVP in the presence of plasticizer through hot-melt extrusion (HME). Computer software was utilized to design a capletshaped tablet. The surface morphology of the printed tablet was assessed using scanning electron microscopy (SEM). The physical form of drug and its integrity following an FDM 3D printing were assessed using $x$-ray powder diffractometry (XRPD), thermal analysis and HPLC. In vitro drug release studies for all 3D printed tablets were conducted in a USP II dissolution apparatus.

Results. Bridging 3D printing process with $\mathrm{HME}$ in the presence of a thermostable filler, talc, enabled the fabrication immediate release tablets at temperatures as low as $110^{\circ} \mathrm{C}$. The integrity of two models drugs was maintained following HME and FDM 3D printing. XRPD indicated that a portion of the loaded theophylline remained crystalline in the tablet. The fabricated tablets demonstrated excellent mechanical properties, acceptable in-batch variability and an immediate in vitro release pattern.

Conclusions. Combining the advantages of PVP as an impeding polymer with FDM 3D printing at low temperatures, this approach holds a potential in expanding the spectrum of drugs that could be used in FDM 3D printing for on demand manufacturing of individualised dosage forms.

KEYWORDS: FDM; fused filament fabrication; HME; patient-specific; immediate release. 


\section{ABBREVIATIONS}

API active pharmaceutical ingredient

CAD computer aided design

DSC differential scanning calorimetry

FDM $\quad$ Fused Deposition Modelling

HME hot melt extrusion

HPLC high performance liquid chromatography

PLA polylactic acid

PVA Poly(vinyl alcohol)

PVP polyvinylpyrrolidone

SEM scanning electron microscopy

$\mathrm{Tg} \quad$ glass transition temperature

Tm melting point

TGA thermal gravimetric analysis

XRPD X-ray powder diffractometry 


\section{INTRODUCTION}

3D printing established roots in various disciplines from arts and engineering to implants and regenerative medicine $(1,2)$. As yet the exploitation of 3D printing for pharmaceutical applications is still at its infancy. However, with the emergence of the first FDA approved 3D printed tablet, Spritam (3), the momentum of this technology is on track to potentially change many means of production for oral dosage forms.

The absence of large array of commercially available API combinations and strengths remains the most frequent problem facing compounding pharmacies today (4). Traditional tableting methods require multiple processing stages, costly facilities and experienced personnel, thus rendering tablet manufacturing impractical when dose modification for one or small group of patients is required. By contrast, 3D printing, not only circumvent these challenges of conventional tabletting, but also offers means of fabricating medicines at the point of dispensing (5). Amongst the different explored 3D printing technologies, fused deposition modelling (FDM) shows significant promise in low-cost dose fabrication (6). This stems up from the fact that FDM printers are available today at low cost and capable of producing 3D objects with a high accuracy and without post-printing steps (7).

Fused deposition modelling (FDM) involves passing a filament based on thermoplastic polymersthrough a hot nozzle, where temperature is eleveted above its glass transition temperature $(\mathrm{Tg})$. The extruded material is deposited layer by layer to form an object, where solidification occurs in less than a second. The potential of FDM 3D printers has been explored in the incorporation of different API molecules through their loading into commercially available PVA filaments (7-9). These previous attempts, however, displayed several limitations such as the use of non-pharmaceutical grade ingredients and limited drug loading $(9,10)$. Previous reports suggested the need for using high temperatures [220 ${ }^{\circ} \mathrm{C}(8), 210^{\circ} \mathrm{C}(9)$ and $250^{\circ} \mathrm{C}(7)$ ] when PVA based dosage forms were fabricated using FDM 3D printers. Moreover, several examples of PLA printed stuctures employed a temperature range of $180-210^{\circ} \mathrm{C}(11-13)$.

Despite the advancement in FDM 3D printing, the array of polymers currently exploited for FDM 3D printing remain limited. The employed polymers for FDM printing in oral drug delivery were restricted to the extended release polymers such as PVA (6-8) and PLA (14). The major limitation of FDM 3D printing renders it unsuitable for the 
production of immediate release tablets, which count for approximately $70 \%$ of all oral dosage forms $(15,16)$. In rare example, our group reported the fabrication of immediate release tablet based on positively charged methacylic polymers (17). Polyvinylpyrrolidone (PVP) is known to have a growing pharmaceutical applications with solubility enhancing abilities (18-20). It is of great interest to adapt this water soluble polymer to fabricate tablet with immediate release profile. In this current work, we explored the feasibility of employing FDM 3D printing to encompass this important polymer in the pharmaceutical field. We have used temperature in this work, up to the authors knowledge, is the lowest to have been explored in constructing drug delivery dosage forms, hence broadening the spectra of materials that could be used with FDM.

\section{MATERIALS AND METHODS}

\section{Materials}

Theophylline (melting point $270{ }^{\circ} \mathrm{C}$ ) (21) was purchased from Acros Organics. Polyvinylpyrrolidone (PVP, MW 40,000) and dipyridamole (melting point $165^{\circ} \mathrm{C}$ ) (22) were purchased from Sigma-Aldrich (UK). Talc was ordered from Fluka Analytical (UK). Triethyl citrate was purchased from Sigma-Aldrich (Dorset,UK) and Scotch blue painter's tape $50 \mathrm{~mm}$ was supplied by $3 \mathrm{M}$ (Bracknell, UK).

\section{Preparation of filaments using HME}

For the preparation of the API-free filaments a Thermo Scientific HAAKE MiniCTW hot melt extruder (Karlsruhe, Germany) was utilised. An optimised ratio of a powder mixture constituting of the polymer (PVP), plasticizer (TEC), filler (talc) and API (theophylline or dipyridamole) at $(50,12.5,27.5$ and $10 \% \mathrm{wt}$ ) respectively, was gradually added to the $\mathrm{HME}$ and allowed to mix for $5 \mathrm{~min}$ at $100{ }^{\circ} \mathrm{C}$ to allow homogenous distribution of the molten mass. Afterwards, extrusion took place at 90 ${ }^{\circ} \mathrm{C}$ at a torque of $0.4 \mathrm{Nm}$.

\section{Tablet design and printing}

Tablets in this study were designed in a caplet shape using an Autodesk ${ }^{\circledR} 3 \mathrm{ds}$ Max $^{\circledR}$ Design 2012 software version 14.0 (Autodesk, Inc., USA). The templates design was then imported to the 3D printer's software in a stereolithography (.stl) file format. For the printing of tablets, pre-prepared filaments were fed into a commercial FDM 3D 
printer equipped with $1.75 \mathrm{~mm}$ nozzle size and MakerWare software Version 2.4.0.17 (Makerbot Industries, LLC., USA). Tablets were printed using modified settings of the software as described earlier in our previous work (23). Tablets were printed using modified settings of the software as follows: type of printer: Replicator 2X; type of filament: PLA; resolution: standard; temperature of building plate: $40{ }^{\circ} \mathrm{C}$; speed of extruder $90 \mathrm{~mm} / \mathrm{s}$ while extruding and $150 \mathrm{~mm} / \mathrm{s}$ while traveling; infill: 100\%; height of the layer: $200 \mu \mathrm{m}$ and nozzle temperature $110{ }^{\circ} \mathrm{C}$. The design was printed without supports or raftsto avoid the need for post-printing finishing step. In order to improve caplet's adhesion to the building plate, a blue Scotch Painter's Tape was applied to the plate's surface.

\section{Thermal analysis}

For modulated temperature differential scanning calorimetry (MTDSC) analysis, a differential scanning calorimeter (DSC) Q2000 (TA Instruments, Elstree, Hertfordshire, UK) with a heating rate of $2{ }^{\circ} \mathrm{C} / \mathrm{min}$ was employed. Each sample was subjected to a heat-cool-heat scan in order to measure and exclude the effect of moisture contents on filament plasticity. A modulated scan was applied using an amplitude of $0.212{ }^{\circ} \mathrm{C}$ and a period of $40 \mathrm{sec}$ was used, scanning from -70 to $200{ }^{\circ} \mathrm{C}$. Analysis was carried out under a purge of nitrogen (50 mL/min). The data was analysed using a TA 2000 analysis software. TA pin-holed lid and $40 \mu \mathrm{L}$ aluminium pans and were filled with approximately $5 \mathrm{mg}$ sample. All measurements were carried out in triplicates.

For TGA analysis, printed tablets, raw materials as well as extruded filaments were measured using a TGA Q5000 (TA Instruments, Hertfordshire, UK). Samples (10 mg ) were added to an aluminium pan without lid. Samples were then heated from $25{ }^{\circ} \mathrm{C}$ to $500^{\circ} \mathrm{C}$ at a heating rate of $10^{\circ} \mathrm{C} / \mathrm{min}$. All measurements were carried out in triplicates.

\section{X-ray Powder diffractometry (XPRD)}

A powder X-ray diffractometer, D2 Phaser with Lynxeye (Bruker, Germany) was used to assess the physical form of APIs in PVP, PVP:TEC filament, API-free and APIloaded filaments, and 3D printed tablets. Samples were scanned from 2Theta $(2 \theta)=$ $5^{\circ}$ to $50^{\circ}$ using $0.01^{\circ}$ step width and a 1 second time count. The divergence slit was 1 $\mathrm{mm}$ and the scatter slit $0.6 \mathrm{~mm}$. The wavelength of the X-ray was $0.154 \mathrm{~nm}$ using $\mathrm{Cu}$ 
source and a voltage of $30 \mathrm{kV}$. Filament emission was $10 \mathrm{~mA}$ using a scan type coupled with a two theta/theta scintillation counter over $30 \mathrm{~min}$.

\section{Characterisation of the tablets properties}

Tablets in this study were characterised for; weight variation, drug content, friability, hardness and disintegration time. For determination of weight uniformity, 20 tablets were randomly selected and weighed individually using a digital analytical balance Ohaus $^{\circledR}$ (Discovery DV215CD). The average weights of the tablets was measured and the percentage deviation from the mean was then determined.

The crushing strength of 10 tablets was measured using a TBH $220 \mathrm{D}($ Erweka $\mathrm{GmbH}$, Heusenstamm, Germany). The friability of the 3D printed tablets was determined using an Erweka Friability Tester TAR 10 (Erweka GmbH, Heusenstamm, Germany). Twenty tablets were randomly selected, weighed and tested at a rotation of $25 \mathrm{rpm}$ for $4 \mathrm{~min}$. Tablets were then collected, dusted and reweighed. The differences in weight were calculated and displayed as a percentage of the original sample weight.

In order to determine the disintegration time for the 3D printed tablets, an Erweka ZT 220 Disintegration tester (Erweka GmbH, Heusenstamm, Germany) was utilised. Six tablets were randomly selected and individually placed in the 6 cylinders of the basket rack assembly. The tablets in the cylinders were then covered with discs and the basket rack was immersed into a beaker containing $750 \mathrm{~mL}$ of $0.1 \mathrm{M} \mathrm{HCl}$ at $37 \pm 0.5$ ${ }^{\circ} \mathrm{C}$. The time required for all tablets to leave the mesh was then visually assessed.

\section{Determination of drug content}

In order to examine the effect of HME and FDM 3D printing on the integrity of drug, API-loaded filaments and 3D printed tablets were analysed for drug content prior and following HME as well as in the 3D printed tablets. Samples (dipyridamole loaded filaments or tablets) were accurately weighed and placed in a $500 \mathrm{~mL}$ of $1: 1$ water:acetonitrile mixture for $2 \mathrm{~h}$ under sonication. The solution were filtered through $0.22 \mu \mathrm{m}$ Millex-GP syringe filters (Merck Millipore, USA) and prepared for HPLC analysis.

Dipyridamole contents in relevant samples were assessed using an Agilent UV-HPLC 1260 series (Agilent Technologies, Inc., Germany) equipped with XTerra RP 18 column (150 x $4.6 \mathrm{~mm}, 5 \mu \mathrm{m}$ particle size) (Waters, Ireland) at temperature $40^{\circ} \mathrm{C}$. The 
mobile phase (60:40 phosphate buffer pH 6.8: acetonitrile) was employed at a flow rate $1 \mathrm{~mL} / \mathrm{min}$ and dipyridamole was detected at a wavelength of $282 \mathrm{~nm}$. The injection volume was $10 \mu \mathrm{L}$ and a stop time was 10 min per sample.

For theophylline, the same UV-HPLC system and column were used as detailed above. A mobile phase constituted of $10 \mathrm{mM}$ solution of ammonium acetate buffer, methanol and acetonitrile (86:7:7) was used. Analysis was carried out at a wavelength of $272 \mathrm{~nm}$, temperature of $40^{\circ} \mathrm{C}$, flow rate of $1 \mathrm{ml} / \mathrm{min}$, injection volume was $5 \mu \mathrm{L}$ and a run time of $7 \mathrm{~min}$.

\section{Scanning electron microscopy (SEM)}

The surface morphology of the filaments and the printed tablets was examined using Quanta-200 SEM microscope at $20 \mathrm{kV}$. Samples were placed on a metallic stub and gold coated under vacuum using JFC-1200 Fine Coater (Jeol, Tokyo, Japan). Photographs of the tablets were also taken with a Canon EOS-1D Mark IV (Canon Ltd, Japan).

\section{In vitro drug release studies}

In vitro drug release studies was investigated using an Erweka DT 600 dissolution tester (USP II). Three tablets were randomly selected and individually placed in the dissolution vessels each containing $900 \mathrm{~mL}$ of $0.1 \mathrm{M} \mathrm{HCL}$ and stirred at $50 \mathrm{rpm}$ and $37 \pm 0.5^{\circ} \mathrm{C}$. Four $\mathrm{mL}$ aliquots were manually collected using $5 \mathrm{~mL}$ Leur-Lok syringes at $(0,5,10,15,20,25,30,40,50,60$ and $70 \mathrm{~min})$ time intervals and filtered through a Millex$\mathrm{HA} 0.45-\mu \mathrm{m}$ filter. Each aliquot withdrawn was replaced with $4 \mathrm{~mL}$ of $0.1 \mathrm{M} \mathrm{HCl}$. The absorbance of the samples were finally measured using a UV spectrophotometer (Bibby Scientific Ltd, UK) at 282 and $272 \mathrm{~nm}$ for dipyridamole and theophylline respectively.

\section{Statistical analysis}

One-way ANOVA was employed using SPSS Software (22.0.0.2) to analyse the results. Differences in results above probability level $(p>0.05)$ was considered not significant whilst; $(p<0.001)$ were considered very significant and between $p=0.01$ and 0.05 were considered significant. 


\section{RESULTS AND DISCUSSION}

Fig. 1 illustrates different step used in the preparation of tablets by combining HME and FDM 3D printing. API, polymer and other filler were physically mixed and processed via HME to produce $1.75 \mathrm{~mm}$ filament at $90^{\circ} \mathrm{C}$. CAD software was used to produce a capsule-shaped tablet that was printed via a benchtop FDM 3D printer.

PVP is frequently used in HME to enhance the dissolution pattern of poorly soluble molecules (24-28). TGA thermographs (Figs. 2A-B) revealed a significant mass loss of PVP filaments around $100{ }^{\circ} \mathrm{C}$ due to dehydration of the PVP filaments. A second mass loss was also apparent at $400{ }^{\circ} \mathrm{C}$ indicating the degradation of PVP. Also the plasticiser TEC degrades at temperatures $>200{ }^{\circ} \mathrm{C}$ (Figs. 2A-B). This renders it unsuitable for FDM 3D printing under the recommended printing temperature of 200$220{ }^{\circ} \mathrm{C}$, thus highlighting the importance of lowering the temperature during the process of 3D printing to suit a variety of APIs and pharmaceutical excipients. The thermal stability of dipyridamole (29) and theophylline (30) were in agreement with previous reports and both APIs were stable at temperatures $<200^{\circ} \mathrm{C}$.

When PVP filament (no filler) were used as a feed for 3D printer, it was not possible to fabricate a structure via FDM 3D printing process due to poor flow from the hot nozzle of printer and the formation of collapsed structure (data not shown). In order to formulate a stable structure and allow rapid solidification of the filament from the hot nozzle of the 3D printer, a thermostable filler, talc (melting points being $>1500{ }^{\circ} \mathrm{C}$ ), was added to the composition of the filament. The latter did not degrade at the temperature range utilised in this study (31).

DSC thermographs, at the first heat-scan, all displayed a large endothermal event in the range of $50-110^{\circ} \mathrm{C}$ due to polymer dehydration (Fig. 3). This might be related to the hygroscopic nature of PVP, where electronegative groups of the carbonyl in pyrrolidone structure are able to from hydrogen bonds with water (32). Therefore, a modulated heat-scan was utilized to assess this event-complex. In order to assess the impact of water on glass transition temperature $(\mathrm{Tg})$, a heat-cool-heat scan was employed. 
The reversing heat flow of the first heat-scan indicated that the Tg of PVP filament (plasticised with TEC) to be in the range of $19-35^{\circ} \mathrm{C}$. This $\mathrm{Tg}$ is significantly lower than expected from Gordon-Taylor equation $\left(\mathrm{Tg}=82.3^{\circ} \mathrm{C}\right)$ and is related to the plasticising effect of water. On the other hand, the second heat-scan indicated a significantly higher $\mathrm{Tg}$ value of $93{ }^{\circ} \mathrm{C}$ (in comparison to the $\mathrm{Tg}$ of first heat-scan, $p<0.05$ ), confirming that moisture has an impact on the plasticity of PVP. Such a plasticizing effect of moisture on PVP was previously reported $(33,34)$.

The addition of talc did not show any significant effect on the thermal behaviour of PVP as noted in the first and second heat-scans. The addition of dipyridamole and theophylline shifted the $\mathrm{Tg}$ of the filament in the second scan from $93^{\circ} \mathrm{C}$ to 73 and 69 ${ }^{\circ} \mathrm{C}$ respectively. Such depression in the $\mathrm{Tg}$ indicates a plasticizing effect of dipyridamole and theophylline. Similar findings have been reported earlier for other API-PVP blends (35).

The XRPD patterns of dipyridamole loaded filament and tablets (Fig.4) showed the absence of peaks at $(2 \theta)=10.13,17.89,18.91,20.42,20.98,23.65,26.12,28.49$, $30.45^{\circ}(36)$, indicating no crystalline presence in the PVP matrices . XRPD spectra for theophylline alone elucidated diffraction peaks at $(2 \theta)=7,12,14$ and $24^{\circ}$ analogous to previous findings $(23,37)$. However, the presence of some peaks at $(2 \theta)=12$ and $7^{\circ}$ indicated that a percentage of theophylline remained in the crystalline form.

In order to examine the effect of hot melt extrusion and 3D printing on the APIs, drug content analysis in the HME extruded filaments prior to 3D printing as well as in the 3D printed tablets was carried out. As elucidated in Fig. 5B, the content of drug was neither affected by HME extrusion nor by 3D printing. Content uniformity was found to be $102.60 \pm 0.59 \%$ and $100.23 \pm 0.09 \%$ for dipyridamole and theophylline, respectively, in the extruded filaments. This high drug content was found to remain the same in the 3D printed tablets (101.18 $\pm 3.91 \%$ and $99.56 \pm 0.48 \%)$ for dipyridamole and theophylline, respectively. In an earlier study, FDM 3D printing at $\left(210^{\circ} \mathrm{C}\right)$ was found to thermally degrade more than half the drug load (5-ASA) (38). Lowering the printing temperature to $110^{\circ} \mathrm{C}$ against the recommended temperature by the $3 \mathrm{D}$ printer manufacturer $\left(230^{\circ} \mathrm{C}\right)(39)$ favours its use for various materials, as reflected by the high drug content in this study. 
Photographs and SEM images showed that the structure of filament was smooth with few apparent gaps or voids (Figs. 1E and 5A). Fabricated tablets were constructed from overlaid layers of filament with an approximate height of $200 \mu \mathrm{m}$. This thickness can be increased to $400 \mu \mathrm{m}$ or decreased into $100 \mu \mathrm{m}$ per layer, as required, via adjusting the resolution of the slicing engine of the printer (23). The potential of utilising FDM 3D printing in modifying the dose to suit patient's individual needs by controlling the volume of the printed drug delivery system has also been demonstrated $(7,23)$.

The 3D printed tablets were evaluated for weight variation, dimensions, hardness and friability (Table I). The friability was reported to be $0 \%$ for all the formulation and the crushing strength required to deform or break the tablets was high $>350 \mathrm{~N}$. These values clearly demonstrates the superiority of FDM 3D printing over other 3D printed technologies such as extrusion-based (40) and powder-based 3D printing $(41,42)$ in terms of producing mechanically strong tablets. The generation of ready-to-use tablets at the end of the printing process without any need for finishing or drying step is another instrumental advantage of FDM 3D printing where individualised dosage forms are instantly fabricated on demand.

The disintegration time of 3D printed tablets was found to be $<15 \mathrm{~min}$ for all tested tablets (Table I). The applicability of utilising the polymer PVP as an immediate release polymer was also demonstrated through the in vitro dissolution of the drugs from the 3D printed tablets. As elucidated in dissolution data (Fig. $5 \mathrm{c}$ ), more than $85 \%$ of dipyridamole and theophylline were released within the first $30 \mathrm{~min}$. This confirms the suitability of PVP as a hydrophilic carrier for engineering immediate release 3D printed dosage forms (43).

In summary, by lowering the temperature of FDM 3D printing process using a hydrophilic polymer, this work reveals the potential of adapting this $3 \mathrm{D}$ printing technology to a wider spectrum of drug molecules and to commonly used immediate release dosage forms. Here, the filament-forming process is HME. However, there are a series of other kinds of filament-forming methods such as wet spinning, dry spinning and electrospinning. $(44,45)$ This work also provides a concept about the combined usage of advanced technologies for creating novel solid dosage forms. 


\section{CONCLUSION}

By combing FDM with HME, it was possible to fabricate 3D printed tablets with immediate release properties based on PVP and talc as a matrix former and a thermostable filler. The tablets were suitable to make two model drugs and achieved immediate release properties. Tablets showed excellent mechanical properties and acceptable in-batch variability. To the authors' knowledge, this is the first report of employing PVP in FDM 3D printing and a rare example of employing the process to produce immediate release tablets. The reported approach can be employed to fabricate patient-tailored tablets at relatively lower temperature $\left(110^{\circ} \mathrm{C}\right)$ and using pharmaceutically approved and solubility enhancing polymer. This work confirms the possibility of expanding the use of FDM 3D printing to a wider range of temperatures for on-demand fabrication of immediate release products.

\section{ACKNOWLEDGMENTS}

The authors would like to thank UCLAN Innovation Team for this support and Mrs Reem Arafat for her help with graphics design. 


\section{List of Tables}

Table I Weight uniformity, API contents, friability, crushing strength, disintegration time and dimensions of PVP based tablets ( $n=3 \pm S T D)$.

\section{List of Figures}

Fig. 1 Schematic illustration of the fabrication of Immediate release 3D-printed tablet. (A) Materials mixture (API, PVP and talc) are processed through HME to produce (B) API loaded PVP filament ( is extruded (C) Stereolithographic file is designed via CAD software and (D) FDM 3D printer uses the filament as a feed to fabricate drug loaded immediate release tablet (E) at $110^{\circ} \mathrm{C}$.

Fig. 2 TGA Thermal degradation profiles of TEC, PVP, PVP:TEC filament, API-free and API loaded filaments, and 3D printed tablets for $(\mathbf{A})$ theophylline and $(\mathbf{B})$ dipyridamole.

Fig. 3 Reversing DSC thermographs of PVP, PVP:TEC filament, API-free and API-loaded filaments, and 3D printed tablets for dipyridamole (A1 First heat-scan and A2 second heatscan) and theophylline (B1 First heat-scan and B2 second heat-scan).

Fig. 4 XRPD patterns of PVP, PVP:TEC filament, API-free and API-loaded filaments, and 3D printed tablets for theophylline $(\mathbf{A})$ and dipyridamole $(\mathbf{B})$.

Fig. 5 (A) Photographs of 3D printed API-loaded tablets, (B) Durg contents before and after HME process and following FDM 3D printing, (C) In vitro dissolution profile of theophylline and dipyridamole from PVP based 3D printed tablets using USPII dissolution apparatus. 
Table I Weight uniformity, API contents, friability, crushing strength, disintegration time and dimensions of PVP based tablets ( $n=3 \pm S T D$ ).

\begin{tabular}{|c|c|c|c|c|c|c|c|c|}
\hline \multirow[t]{2}{*}{ Drug } & \multirow{2}{*}{$\begin{array}{l}\text { Weight } \\
\text { Uniformity } \\
\pm \text { SD (mg) }\end{array}$} & \multirow{2}{*}{$\begin{array}{l}\text { Drug } \\
\text { content } \\
\pm \text { SD (\%) }\end{array}$} & \multirow[t]{2}{*}{$\begin{array}{l}\text { Friability } \\
\text { (\%) }\end{array}$} & \multirow{2}{*}{$\begin{array}{l}\text { Crushing } \\
\text { strength } \\
\text { (N) }\end{array}$} & \multirow[t]{2}{*}{$\begin{array}{l}\text { Disintegration } \\
\text { time (min) }\end{array}$} & \multicolumn{3}{|c|}{$\begin{array}{l}\text { Tablet Dimensions } \\
\text { (Length X Width X Height) }\end{array}$} \\
\hline & & & & & & $\begin{array}{l}\mathrm{L} \pm \mathrm{SD} \\
(\mathrm{mm})\end{array}$ & $\begin{array}{l}W \pm S D \\
(\mathrm{~mm})\end{array}$ & $\begin{array}{l}\mathrm{H} \pm \mathrm{SD} \\
(\mathrm{mm})\end{array}$ \\
\hline \multirow[t]{2}{*}{ Dipyridamole } & $121.68 \pm$ & $101.18 \pm$ & 0 & 432.67 & 10 & 9.23 & 3.86 & 3.80 \\
\hline & 9.28 & 3.91 & & & & \pm 0.15 & \pm 0.09 & \pm 0.12 \\
\hline \multirow[t]{2}{*}{ Theophylline } & $111.01 \pm$ & 99.56 & 0 & 379.00 & 13 & 9.43 & 3.65 & 3.54 \\
\hline & 5.30 & \pm 0.48 & & & & \pm 0.07 & \pm 0.02 & \pm 0.08 \\
\hline
\end{tabular}




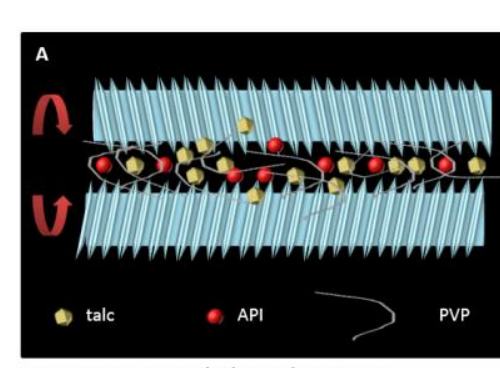

Twin-screw compounder hot-melt extrusion

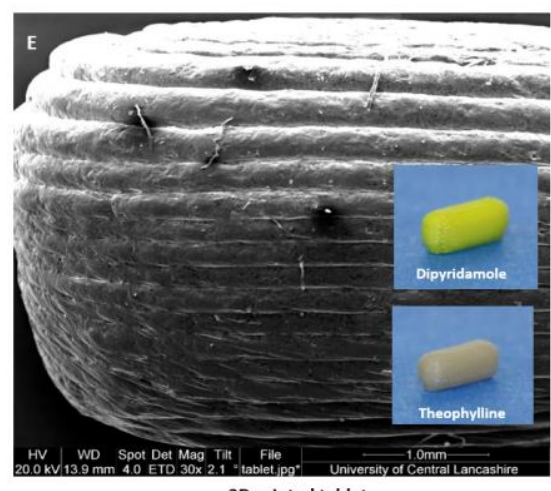

3D printed tablet

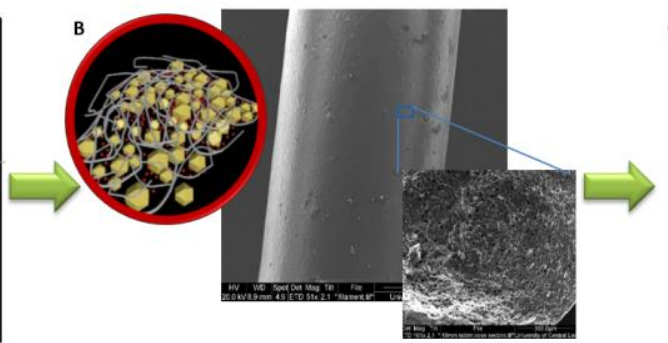

API-loaded PVP filament

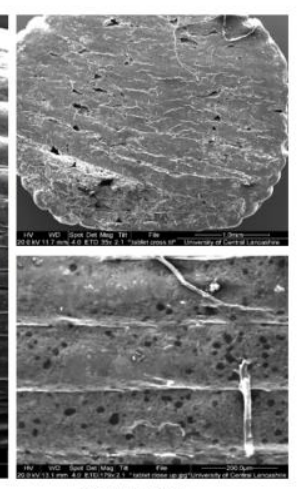

Cross-section
C
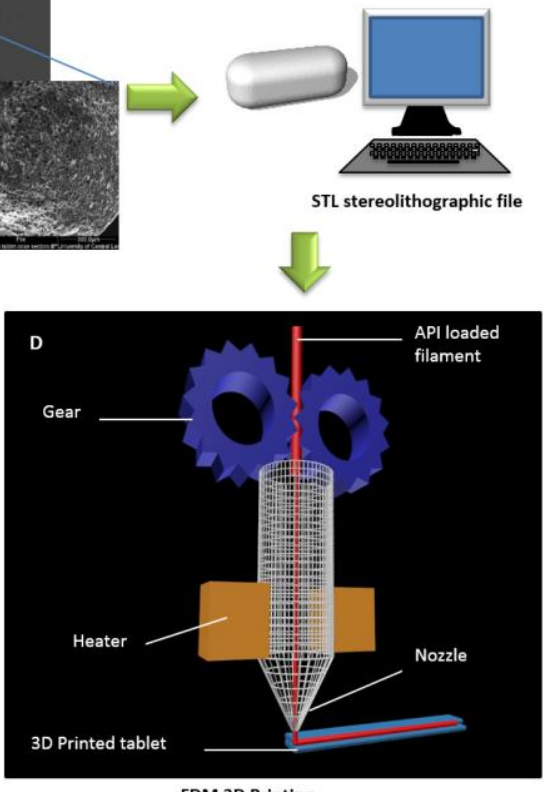

FDM 3D Printing

Fig. 1 Schematic illustration of the fabrication of Immediate release 3D-printed tablet. (A) Materials mixture (API, PVP and talc) are processed through HME to produce (B) API loaded PVP filament ( is extruded (C) Stereolithographic file is designed via CAD software and (D) FDM 3D printer uses the filament as a feed to fabricate drug loaded immediate release tablet (E) at $110^{\circ} \mathrm{C}$. 

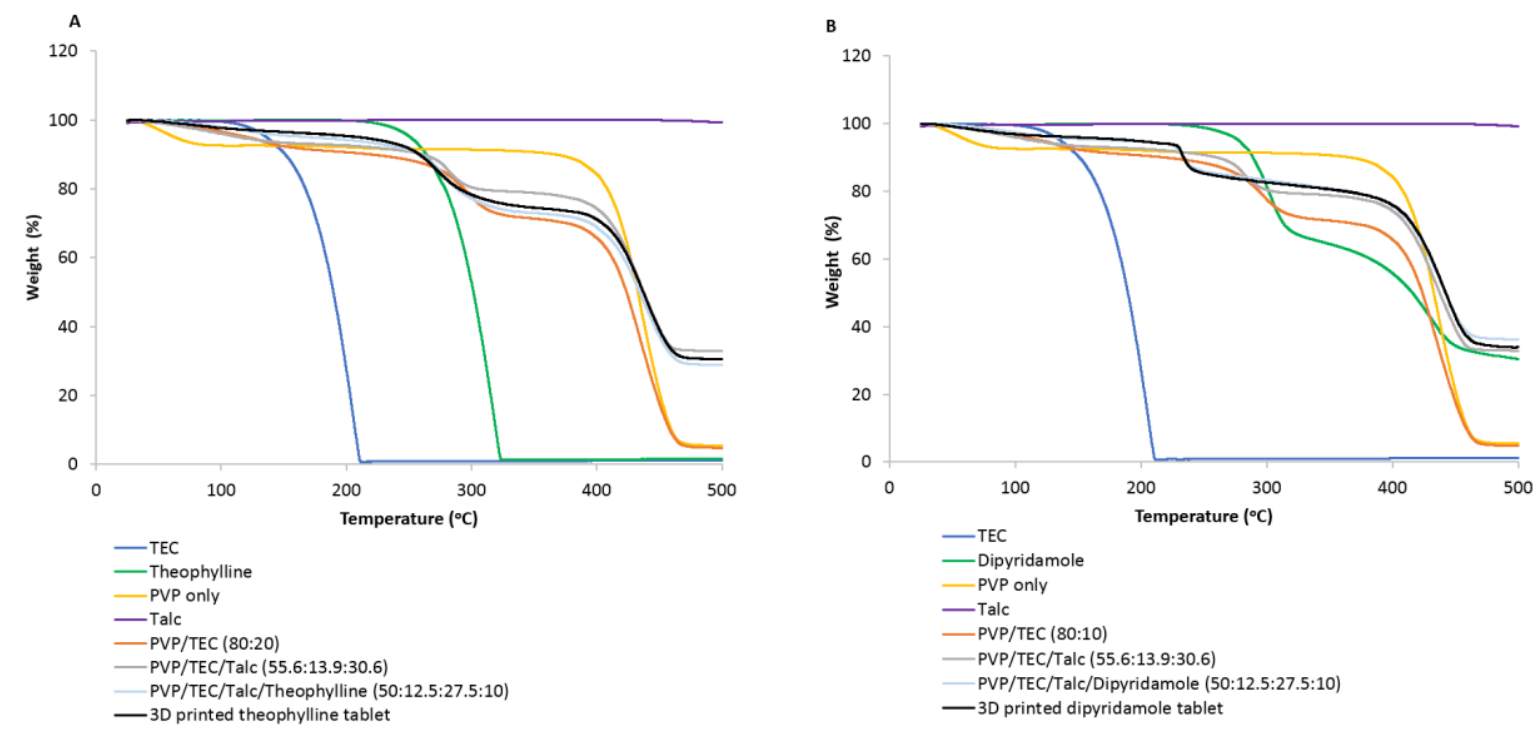

Fig. 2 TGA Thermal degradation profiles of TEC, PVP, PVP:TEC filament, API-free and API loaded filaments, and 3D printed tablets for $(\mathbf{A})$ theophylline and $(\mathbf{B})$ dipyridamole. 
A1

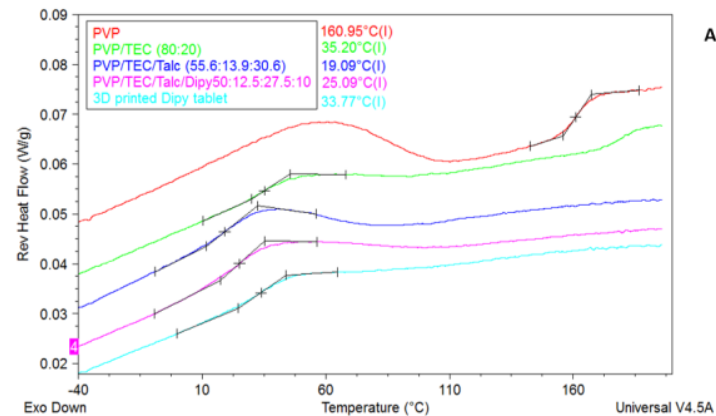

B1

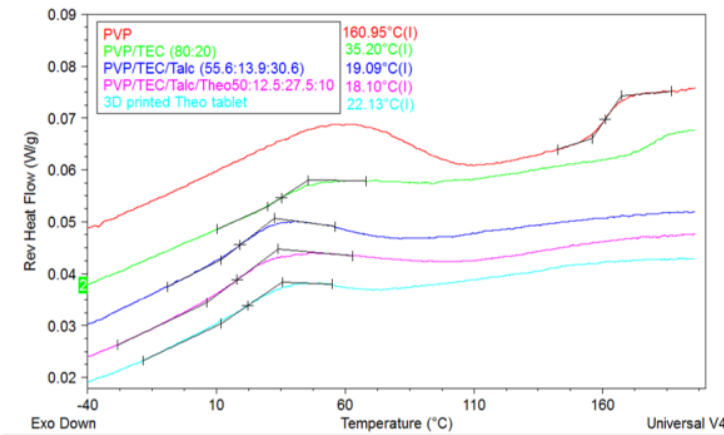

A2

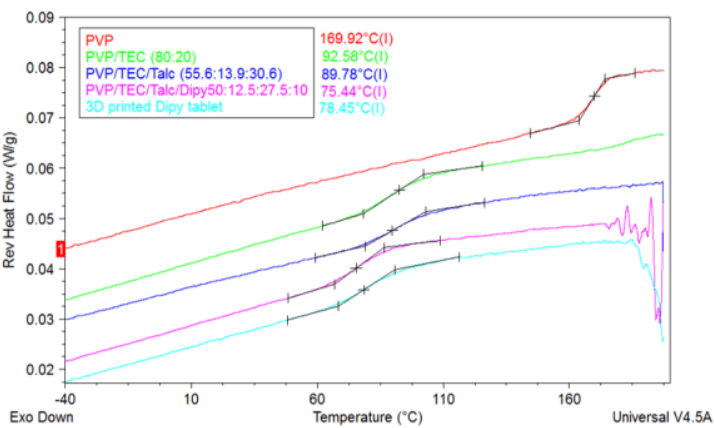

B2

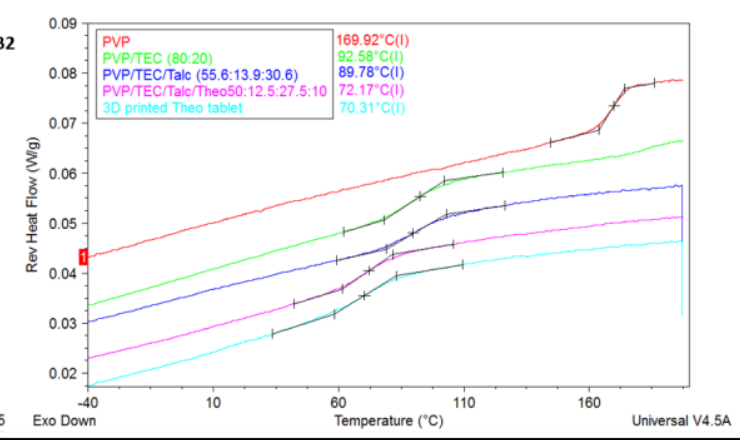

Fig. 3 Reversing DSC thermographs of PVP, PVP:TEC filament, API-free and API-loaded filaments, and 3D printed tablets for dipyridamole (A1 First heat-scan and A2 second heatscan) and theophylline (B1 First heat-scan and B2 second heat-scan). 


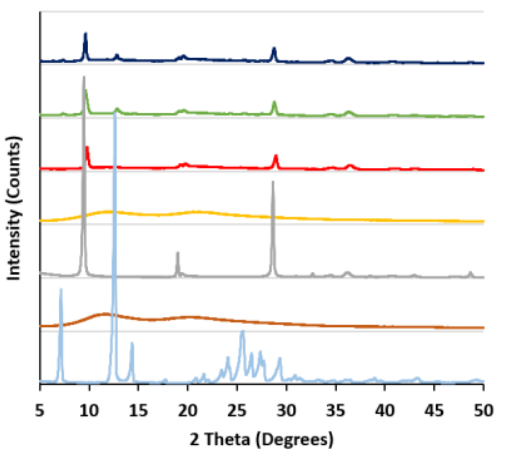

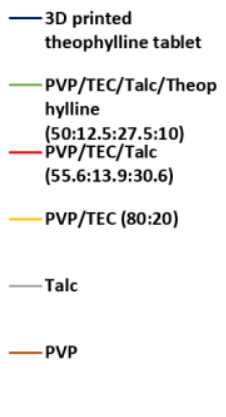

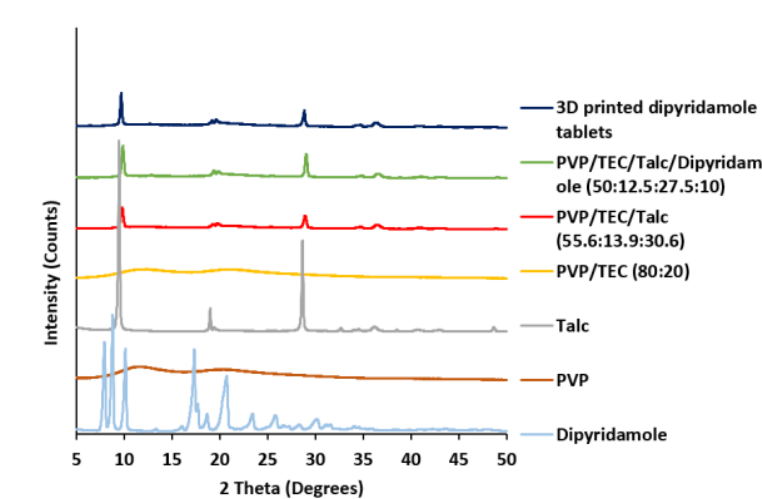

Fig. 4 XRPD patterns of PVP, PVP:TEC filament, API-free and API-loaded filaments, and 3D printed tablets for theophylline $(\mathbf{A})$ and dipyridamole $(\mathbf{B})$. 
A

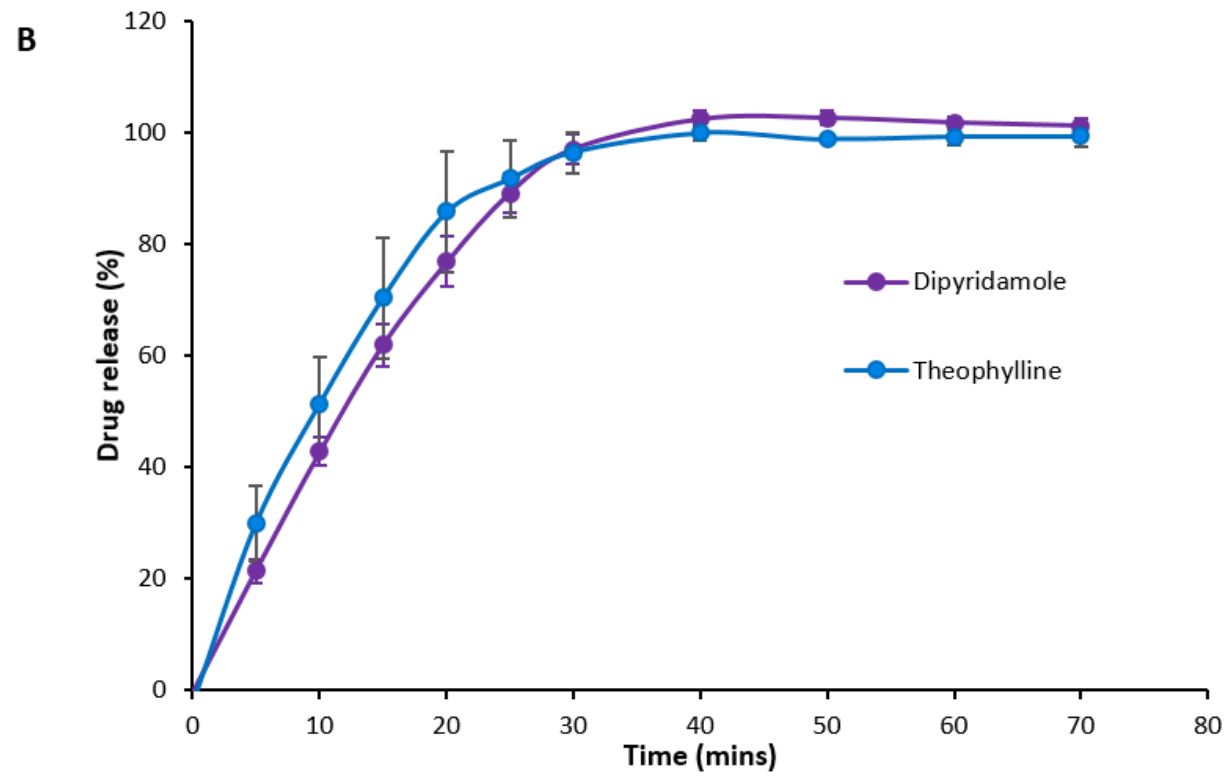

Fig. 5 (A) Photographs of 3D printed API-loaded tablets, (B) Durg contents before and after HME process and following FDM 3D printing, (C) In vitro dissolution profile of theophylline and dipyridamole from PVP based 3D printed tablets using USPII dissolution apparatus. 


\section{REFERENCES}

1. Chung P, Heller JA, Etemadi M, Ottoson PE, Liu JA, Rand L, Roy S. Rapid and low-cost prototyping of medical devices using 3D printed molds for liquid injection molding. Journal of visualized experiments : JoVE. 2014(88):e51745.

2. Dombroski CE, Balsdon ME, Froats $A$. The use of a low cost 3D scanning and printing tool in the manufacture of custom-made foot orthoses: a preliminary study. BMC research notes. 2014;7:443.

3. Aprecia. Zipdose ${ }^{\circledR}$ technology. 12/3/2015. Available from: https://aprecia.com/zipdoseplatform/zipdose-technology.php.

4. McLean S, Sheikh A, Cresswell K, Nurmatov U, Mukherjee M, Hemmi A, Pagliari C. The Impact of Telehealthcare on the Quality and Safety of Care: A Systematic Overview. Plos One. 2013;8(8).

5. Sanderson K. 3D printing: the future of manufacturing medicine? Pharm J. 2015;7865.

6. Goyanes A, Robles Martinez P, Buanz A, Basit AW, Gaisford S. Effect of geometry on drug release from 3D printed tablets. International journal of pharmaceutics. 2015;494(2):657-

663.

7. Skowyra J, Pietrzak K, Alhnan MA. Fabrication of extended-release patient-tailored prednisolone tablets via fused deposition modelling (FDM) 3D printing. European Journal of Pharmaceutical Sciences. 2015;68:11-17.

8. Goyanes A, Buanz ABM, Basit AW, Gaisford S. Fused-filament 3D printing (3DP) for fabrication of tablets. International Journal of Pharmaceutics. 2014;476(1-2):88-92.

9. Goyanes A, Buanz AB, Hatton GB, Gaisford S, Basit AW. 3D printing of modified-release aminosalicylate (4-ASA and 5-ASA) tablets. Eur J Pharm Biopharm. 2015;89:157-162.

10. Goyanes A, Chang H, Sedough D, Hatton GB, Wang J, Buanz A, Gaisford S, Basit AW. Fabrication of controlled-release budesonide tablets via desktop (FDM) 3D printing. Int J Pharm. 2015;496(2):414-420.

11. Boetker J, Water JJ, Aho J, Arnfast L, Bohr A, Rantanen J. Modifying release characteristics from 3D printed drug-eluting products. Eur J Pharm Sci. 2016.

12. Rosenzweig DH, Carelli E, Steffen T, Jarzem P, Haglund L. 3D-Printed ABS and PLA Scaffolds for Cartilage and Nucleus Pulposus Tissue Regeneration. Int J Mol Sci. 2015;16(7):1511815135.

13. Senatov FS, Niaza KV, Zadorozhnyy MY, Maksimkin AV, Kaloshkin SD, Estrin YZ. Mechanical properties and shape memory effect of 3D-printed PLA-based porous scaffolds. J Mech Behav Biomed Mater. 2016;57:139-148.

14. Sandler N, Salmela I, Fallarero A, Rosling A, Khajeheian M, Kolakovic R, Genina N, Nyman J, Vuorela $\mathrm{P}$. Towards fabrication of 3D printed medical devices to prevent biofilm formation. International Journal of Pharmaceutics. 2014;459(1-2):62-64.

15. Marketsandmarkets. Drug delivery technology market. 15/10/2015. Available from: http://www.marketsandmarkets.com/Market-Reports/drug-delivery-technologies-market1085.html?gclid=CIXRuMT5osQCFe6WtAodmiUAZg.

16. GBIResearch. Oral drug delivery market report. 16/11/2015. Available from: http://www.contractpharma.com/issues/2012-06/view features/oral-drug-delivery-marketreport/.

17. Pietrzak K, Isreb A, Alhnan MA. A flexible-dose dispenser for immediate and extended release 3D printed tablets. European journal of pharmaceutics and biopharmaceutics : official journal of Arbeitsgemeinschaft fur Pharmazeutische Verfahrenstechnik eV. 2015.

18. Knopp MM, Olesen NE, Holm P, Langguth P, Holm R, Rades T. Influence of Polymer Molecular Weight on Drug-polymer Solubility: A Comparison between Experimentally Determined Solubility in PVP and Prediction Derived from Solubility in Monomer. Journal of Pharmaceutical Sciences. 2015;104(9):2905-2912. 
19. Shah J, Vasanti S, Anroop B, Vyas H. Enhancement of dissolution rate of valdecoxib by solid dispersions technique with PVP K 30 \& PEG 4000: preparation and in vitro evaluation. Journal of Inclusion Phenomena and Macrocyclic Chemistry. 2008;63(1):69-75.

20. Sharma A, Jain CP. Preparation and characterization of solid dispersions of carvedilol with PVP K30. Research in Pharmaceutical Sciences. 2010;5(1):49-56.

21. SIGMA-ALDRICH. Theophylline melting point standard. 2016 16/06. Available from: http://www.sigmaaldrich.com/catalog/product/sial/phr1151?lang=en\&region=GB.

22. SIGMA-ALDRICH. Dipyridamole. 2016 16/06. Available from: http://www.sigmaaldrich.com/catalog/product/sigma/d9766?lang=en\&region=GB.

23. Pietrzak K, Isreb A, Alhnan MA. A flexible-dose dispenser for immediate and extended release 3D printed tablets. Eur J Pharm Biopharm. 2015;96:380-387.

24. Agrawal AM, Dudhedia MS, Patel AD, Raikes MS. Characterization and performance assessment of solid dispersions prepared by hot melt extrusion and spray drying process. Int J Pharm. 2013;457(1):71-81.

25. Alsulays BB, Park JB, Alshehri SM, Morott JT, Alshahrani SM, Tiwari RV, Alshetaili AS, Majumdar S, Langley N, Kolter K, Gryczke A, Repka MA. Influence of Molecular Weight of Carriers and Processing Parameters on the Extrudability, Drug Release, and Stability of Fenofibrate Formulations Processed by Hot-Melt Extrusion. J Drug Deliv Sci Technol. 2015;29:189-198.

26. Agrawal A, Dudhedia M, Deng W, Shepard K, Zhong L, Povilaitis E, Zimny E. Development of Tablet Formulation of Amorphous Solid Dispersions Prepared by Hot Melt Extrusion Using Quality by Design Approach. AAPS PharmSciTech. 2016;17(1):214-232.

27. LaFountaine JS, Prasad LK, Brough C, Miller DA, McGinity JW, Williams RO, 3rd. Thermal Processing of PVP- and HPMC-Based Amorphous Solid Dispersions. AAPS PharmSciTech. 2016;17(1):120-132.

28. Martinez-Marcos L, Lamprou DA, McBurney RT, Halbert GW. A novel hot-melt extrusion formulation of albendazole for increasing dissolution properties. Int J Pharm. 2016;499(12):175-185.

29. Alexander V. Gerasimov MAZ, Valery V. Gorbatchuk, Liana S. Usmanova. Increasing the solubility of dipyridamole using polyethylene glycols. International Journal of Pharmacy and Pharmaceutical Sciences. 2014;6(9):244-247.

30. Silva Oliveira M, Miguel Agustinho SC, Guzzi Plepis AMd, Tabak M. On the Thermal Decomposition of Dipyridamole: Thermogravimetric, Differential Scanning Calorimetric and Spectroscopic Studies. Spectroscopy Letters. 2006;39(2):145-161.

31. Enderle JD, Bronzino JD, Blanchard SM. Introduction to Biomedical Engineering: Elsevier Academic Press; 2005.

32. Verdonck E, Schaap K, Thomas LC. A discussion of the principles and applications of Modulated Temperature DSC (MTDSC). International Journal of Pharmaceutics. 1999;192(1):3-20.

33. Szakonyi G, Zelkó R. The effect of water on the solid state characteristics of pharmaceutical excipients: Molecular mechanisms, measurement techniques, and quality aspects of final dosage form. International Journal of Pharmaceutical Investigation. 2012;2(1):18-25.

34. Lai MC, Hageman MJ, Schowen RL, Borchardt RT, Laird BB, Topp EM. Chemical stability of peptides in polymers. 2. Discriminating between solvent and plasticizing effects of water on peptide deamidation in poly(vinylpyrrolidone). Journal of Pharmaceutical Sciences. 1999;88(10):1081-1089.

35. Nair R, Nyamweya N, Gönen S, Martínez-Miranda L, Hoag SW. Influence of various drugs on the glass transition temperature of poly(vinylpyrrolidone): a thermodynamic and spectroscopic investigation. International Journal of Pharmaceutics. 2001;225(1-2):83-96. 
36. Vepuri SB. Studies based on supramolecular chemistry in drug design and improvement of pharmaceutical solids. In.Department of Pharmacy: Acharya Nagarjuna University; 2014. p.

212.

37. Rasanen E, Rantanen J, Jorgensen A, Karjalainen M, Paakkari T, Yliruusi J. Novel identification of pseudopolymorphic changes of theophylline during wet granulation using near infrared spectroscopy. J Pharm Sci. 2001;90(3):389-396.

38. Goyanes A, Buanz AB, Hatton GB, Gaisford S, Basit AW. 3D printing of modified-release aminosalicylate (4-ASA and 5-ASA) tablets. European journal of pharmaceutics and biopharmaceutics : official journal of Arbeitsgemeinschaft fur Pharmazeutische Verfahrenstechnik eV. 2014.

39. Makerbot. Replicator 2X Experimental 3D Printer User Manual., http://downloads.makerbot.com/replicator2x/MakerBot Replicator2X UserManual Eng.pd fln.; 2013.

40. Khaled SA, Burley JC, Alexander MR, Roberts CJ. Desktop 3D printing of controlled release pharmaceutical bilayer tablets. International Journal of Pharmaceutics. 2014;461(1-2):105111.

41. Yu D-G, Branford-White C, Yang Y-C, Zhu L-M, Welbeck EW, Yang X-L. A novel fast disintegrating tablet fabricated by three-dimensional printing. Drug Dev Ind

Pharm. 2009;35(12):1530-1536.

42. Katstra WE, Palazzolo RD, Rowe CW, Giritlioglu B, Teung P, Cima MJ. Oral dosage forms fabricated by Three Dimensional Printing ${ }^{\mathrm{TM}}$. J Control

Release. 2000;66(1):1-9.

43. Liu X, Lu M, Guo Z, Huang L, Feng X, Wu C. Improving the chemical stability of amorphous solid dispersion with cocrystal technique by hot melt extrusion. Pharm Res. 2012;29(3):806817.

44. Yu DG, Li XY, Wang X, Yang JH, Bligh SW, Williams GR. Nanofibers Fabricated Using Triaxial Electrospinning as Zero Order Drug Delivery Systems. ACS Appl Mater Interfaces. 2015;7(33):18891-18897.

45. Yang C, Yu DG, Pan D, Liu XK, Wang X, Bligh SWA, Williams GR. Electrospun pH-sensitive core shell polymer nanocomposites fabricated using a tri-axial process. Acta Biomater. 2016;35:77-86. 